\title{
A Study on the Development of Information-based Teaching Ability of Rural Primary English Teachers in Leshan City
}

\author{
Ye Zhou \\ School of Foreign Languages, Leshan Normal University, Leshan, Sichuan, China
}

\begin{abstract}
In the modern society and the information era, information-based teaching ability is a must for primary school English teachers. Thanks to the wide use of information technology in schools, the education system has witnessed big changes in the past few years, which poses new challenges to primary school English teachers. But in western rural areas in China, most primary school English teachers are poorly-trained in terms of information-based teaching. The study takes rural primary school English teachers in Leshan City, Sichuan, China as the research object, taking advantage of approaches like questionnaire survey and interviews, etc. Based on the analysis of the status quo and the influence factors of information-based teaching ability of rural primary school English teachers, the study aims to put forward strategies in order to improve the development of information-based teaching ability of the rural primary school English teachers.
\end{abstract}

Keywords: Information-based teaching ability; Development; Rural primary english teachers; Leshan city.

(9) (1) CC BY: Creative Commons Attribution License 4.0

\section{Introduction}

With the development of modern society, the modernization of education will be realized only when teachers meet the requirement of the educational informatization and develop their information-based teaching ability. In terms of rural teachers, Ministry of Education in China specifically sets goals to improve their teaching quality. Furthermore, with the reform of new curriculum, teachers' traditional roles in the classroom as lecturers have been changed to facilitators, assessors, prompters, observers and managers, etc. And in the information era, teachers' instruction is no longer the only knowledge sources with the diverse resources of teaching information. In this case, modern teachers are supposed to play many new roles in the classroom such as creators of the learning atmosphere, collectors of information resources, and designers of teaching tasks with the help of computers and the internet.

Admittedly, there is a great difference between rural and urban areas in terms of modern teaching facilities. So it is urgent to improve the development of information-based teaching ability of the rural teachers. But unfortunately, current training quality is far from satisfaction.

The study takes rural primary school English teachers in Leshan City, Sichuan, China as the research object in that Leshan City is located in the southwest of China with relatively low level both in economy and education. Specifically, the study probes into the current situation of information-based teaching ability of rural primary school English teachers in Leshan City, analyzes the influencing factors and existing problems, and further puts forward some strategies to solve the problems accordingly, in order to make contribution to the development of informationbased teaching ability of the rural teachers and even contribute to the rural basic education.

\section{Literature Review}

In Education in China: National Education Development in 2013 released by Ministry of Education in 2015, it is pointed out that although a certain degree of success has been achieved in the construction of information-based teaching in elementary and secondary schools, imbalanced distribution of resources still exists in different areas due to different economic power and different degree of emphasis by authorities as well as different investment by the local governments. Thus, with relatively short development of Chinese educational informatization and poor infrastructure compared to advanced countries, there is still a long way to go in the field.

Up to now, the study on the development of teachers' information-based teaching ability is a hot topic in China. The domestic researchers share in common that information-based competence refers to the ability to make use of computers and the internet to acquire information related to the teaching and the ability to manage and design teaching tasks on the basis of the information. Specifically, Peng (2007) points out that only when teachers in information era are qualified in teaching ability, information literacy, scientific research capacity and lifelong learning ability can they meet the requirement of modern education and information-based teaching. Li Tianlong (2009), holds that information-based teaching ability mainly consists of the following 6 aspects: integration ability of information and curriculum, design ability of information-based teaching, development ability of information-based teaching resources, implementation ability of information-based teaching, assessment ability of information-based teaching and supervision ability of information-based teaching.

As for the status quo analysis and countermeasures to improve the information-based teaching ability of teachers, Xi (2011) points out that the current problems include low utilization ratio and teachers' lack of information-based teaching concept and further puts forward some countermeasures such as actively linking schools 
with enterprises to improve the usage efficiency of multi-media facilities and carrying out different kinds of academic forums to strengthen teachers' consciousness of information-based teaching. After carrying out questionnaire survey and on-the-spot investigation in 26 secondary schools, 13 rural middle schools, 13 rural elementary schools and 26 village-level elementary schools of 13 counties in Gan Su Province, China in terms of teachers' cognition, attitude, teaching concept, teaching ability, teaching process and development of teaching resources with respect to information-based teaching, Li and Zhang (2011) gives the following advice: improving training content, updating teaching concept, combining theory with practice, creating campus atmosphere for information-based teaching and carrying out effective reflection and communication among teachers, etc.

Judging from other researches, the author finds out that there is rarely study on rural primary school English teachers in Leshan City. And this study will do the job.

\section{Research Design \\ 3.1. Research Subjects}

Jingyan County, Leshan City is the hometown of the author's husband so it is very convenient for the writer to do the research. And many primary English teachers in Jingyan Country have been trained in the author's working unit, Leshan Normal University. Besides, some primary English teachers in Jingyan County are previous students of the author's husband so the writer can ask them to hand out the questionnaires to their colleagues and carry out the interviews. Totally, the author has chosen 50 rural primary English teachers in all 26 primary schools in Jingyan County as the research objects.

\subsection{Questionnaire Design}

The questionnaire on information-based teaching ability is named Status Quo of Information-based Teaching Ability Development of Rural Primary English Teachers in Leshan City, categorized into the following aspects:

1. Personal information;

2. Personal attitude and consciousness about information-based teaching;

3. Current information-based teaching ability;

4. Informatization atmosphere of the school;

5. Training about information-based teaching.

A few specific questions are listed:

1. Do you have computer in your office and is the internet available?

2. Do you often use multi-media facilities to aid your teaching?

3. Have you compared the teaching effect between teaching with information-based facilities and without?

4. What will you do if you need new teaching resources?

5. Are you familiar with how to make courseware by means of computers and the internet?

6. Does your school's authority put emphasis on information-based teaching ability?

$\cdots$

\subsection{Procedures}

First, the author distributed the questionnaires to all the 50 rural primary English teachers. Then, all of them are required to finish the questionnaires honestly and anonymously. Finally, the writer recollected the questionnaires. All the 50 questionnaires were valid and the author put the data into the computer for statistical analysis by SPSS16.0. During the study, the author also carried out some interviews with teachers of different ages and from different schools.

\section{Major Findings of the Research Results}

According to the analysis of questionnaire and interviews, the author reaches a conclusion that the informationbased teaching ability of rural primary English teachers in Leshan City remains to be improved.

First, in terms of personal information, the writer finds out that most teachers are young and middle-aged and all of them are qualified in educational background. But there is one thing obvious, that is, female teachers far outnumber male teachers. Female teachers are often disturbed by their family stuff, so their time and energy put into teaching are affected to some degree.

Secondly, in terms of personal attitude and consciousness about information-based teaching, most of them use information-based teaching facilities out of schools' requirement, not their own interest. They think it is pretty enough to use computers and surf on the internet, which shows a poor consciousness about information-based teaching.

Thirdly, in terms of current information-based teaching ability, most teachers have mastered basic computer skills like PPT but lack new and advanced technology. For example, they still have problems using informationbased techniques to get the feedback of the teaching and to establish electronic records of the students.

Fourthly, in terms of informatization atmosphere of the school, not all the classrooms are equipped with a set of information-based teaching facilities including computers, projectors, projecting screen and interactive whiteboard, etc. Although the authority does stress on information-based teaching, lack of money is still a problem for some poor schools. Furthermore, most software or platform needs additional expense if more resources are needed. Therefore, in most schools, computers fail to do the best they can. 
Finally, in terms of training about information-based teaching, the teachers seldom take part in training related to information-based teaching. And the occasional training is mostly about theory instead of practice.

\section{Influencing Factors for Information-Based Teaching Ability Development}

After analyzing the major findings of the research, the author further concluded the following influencing factors for information-based teaching ability development of the rural primary English teachers.

\subsection{Money Factor}

In rural area, education funds have always been a problem. The construction of information-based teaching, the purchase of teaching resources and high-quality training are all based on education funds. Therefore, money plays an important role in construction of information-based teaching.

\subsection{School Factor}

The school lacks guarantee mechanism and incentive system. Because of limited money, there is no guarantee for information-based teaching. Only in demonstration lessons, multi-media facilities are used. In daily teaching, traditional teaching method prevails. Thus, school authority and related policy are key factors influencing information-based teaching.

\subsection{Teachers Factor}

Most teachers are burdened with heavy teaching tasks and female English teachers are further burdened by family routines. Besides, most teachers depend too much on PPT, which is still a kind of teacher-centered teaching approach and greatly hinder them from making use of other information-based teaching approaches. In addition, most teachers take part in training related to information-based teaching out of school's order, not their own initiatives, which results in low training quality.

\subsection{Students Factor}

It is known that students' interest is a vital factor influencing teachers' teaching effect. In this case, informationbased teaching should be designed in a students-centered way so that students' attention can be focused and learning curiosity and innovation ability can be aroused.

\subsection{Training Factor}

Training quality directly decides how well the teachers can improve their information-based teaching ability. Unfortunately, most of the training is formalistic, focusing more on theory instead of practice. In addition, the certificate of training is so easy to get that the teachers' information-based teaching ability is not improved.

\section{Strategies for Information-Based Teaching Ability Development}

Based on the above-mentioned research findings and influencing factors, the author puts forward the following strategies for improving the information-based teaching ability development of rural English teachers accordingly.

\subsection{Capital Investment}

The country should continue to increase capital investment in education, especially to rural areas. Meanwhile, the country should implement other measures to tackle this problem, such as encouraging powerful companies and enterprises donate information-based teaching facilities to the poverty-stricken areas and schools or carrying out "one-to-one support" programs between cities and countryside.

\subsection{School Policy}

First, the school should recruit more English teachers so as to reduce the heavy teaching tasks of current teachers, making them have more time and energy to improve themselves. Secondly, the schools should improve their system construction related to information-based teaching, creating an informatization atmosphere on campus. Thirdly, the school authority should stimulate the teachers' development of information-based teaching ability both by spiritual and material awards and even make information-based teaching ability as a necessity in teachers' promotion of titles. Finally, the school authority should choose high-quality information-based training around the nation and encourage teachers to join the training.

\subsection{Teachers}

In the first place, the teachers should convert their wrong belief that current qualification is enough to teach the students. They need to improve themselves with lifelong learning concept. Besides, they need to build the consciousness of information-based teaching and change the traditional teacher-centered class. Finally, they need to realize that information-based training is not just a compulsory task assigned by the school but a precious opportunity to improve themselves, which is of great importance to their teaching career. 


\subsection{Students}

Students are full of curiosity and energy, so they are supposed to be interested in information-based learning. And chances are that students are more familiar with the internet to some degree than the teachers. Some top students with learning initiatives may know some access to learning English enjoyably and effectively. The teachers should set them to be the good example for other students to follow. Only when the students are encouraged to search for learning resources in an information-based atmosphere can the students-centered class be realized.

\subsection{Training}

First, training time should be adjusted. Traditional training time is often mandatorily arranged in summer or winter vacation, which incurs teachers' disfavor and in turn affects the training quality. In comparison, term-time training would be more popular with the teachers in that they can put what they have just learned into practice, which is a win-win situation for teachers and students. Secondly, training methods should be diversified. Specifically, case teaching, face-to-face teaching, reflection training and serving temporary positions in informationbased companies or enterprises can be combined so as to promote the overall development of the teachers' information-based teaching ability. Finally, evaluation mechanism of training should be improved. A set of complete evaluation mechanism is of great importance to the teachers' professional development. Before-training, in-training and after-training programs are necessary to improve the efficiency of the teachers' information-based training.

\section{Conclusion}

The high development of technology triggers the innovation of education and simultaneously poses new opportunities and challenges to teachers and schools. The current situation of rural schools' informatization atmosphere and teachers' information-based ability remains to be improved. Only when the educational administrators, the school authority, the companies or enterprises, the teachers and the students make joint efforts can the rural teachers' information-based ability develop and the information-based education really be implemented in China.

\section{Acknowledgement}

This paper is sponsored by Sichuan Primary and Secondary School Teachers' Professional Development Research Center (PDTR2017-05).

\section{Reference}

$\mathrm{Li}$ and Zhang, J. (2011). Strategies study of information-based teaching ability development of rural primary and secondary teachers in Gansu province. China. 7.

Li Tianlong (2009). Study on development of information-based teaching ability of Young University Teachers. Shaanxi Normal University: Xian. 5.

Peng, L. (2007). Effective teaching, Problems and countermeasures in information-based teaching. Northeast Normal University Press: Chang Chun. 41-43.

Xi, T. (2011). Status Quo of application of information technology in subject teaching and countermeasures. Shandong Normal University. 34. 